\title{
Detoxification of sugarcane hemicellulosic hydrolyzate using a fixed bed column packed with encapsulated lamellar double hydroxide
}

\author{
Davi O. Emirandetti, Beatriz M. Travália, Marcus B. S. Forte.
}

\begin{abstract}
Brazil is the world's largest producer of sugarcane. The lignocellulosic biomass of sugarcane (bagasse) is an excellent source for use in bioprocesses, once removed the inhibitory compounds formed during the pretreatment of the biomass. To remove them, the use of lamellar double hydroxides (LDH) as an adsorbent has been proposed. In this context, the aim of this work was to develop a process that allows the detoxification of the sugarcane hydrolyzate in a fixed bed column packed with LDH encapsulated in alginate. A complete experimental design (CCRD) was used to study the effect of the mass of adsorbent, flow and temperature on the adsorption of the inhibitors. Furfural and Hydroxymethylfurfural, the main inhibitors, were seletively removed. Intermediate temperature, greater mass of adsorbent and higher flow favored their adsorption. Acetic acid and sugars were not separated.
\end{abstract}

\section{Key words:}

Adsorption, detoxification, hemicellulosic hydrolyzate

\section{Introduction}

Brazil is the world's largest producer of sugarcane, with production forecast for the 2018/19 crop of 620.4 million tons ${ }^{1}$. In order to be used in bioprocesses, the sugarcane lignocellulosic biomass (straw and bagasse) must undergo a pretreatment step, which releases fermentable sugars by breaking the bonds between cellulose, hemicellulose and lignin. However, since the pretreatment can produce inhibitory compounds that are toxic to the fermentative microorganisms, such as acetic acid and furanics; a detoxification process is necessary to remove these inhibitors $^{2}$. This detoxification can be carried out with adsorption processes using alternative adsorbents, as is the case with Lamellar Double Hydroxides (LDH's). LDH is a mineral solid that has great adsorption capacity due to the large surface area of its interlamellar spaces, which can be occupied by different molecules ${ }^{3}$.

In this context, the aim of this work was to develop a process that allows the detoxification of the sugarcane hemicellulosic hydrolyzate in a fixed bed column packed with LDH encapsulated in alginate.

\section{Results and Discussion}

The LDH (hydrotalcite type, with $70 \% \mathrm{MgO}$ ) was firstly calcined at $500{ }^{\circ} \mathrm{C}$ for four hours, to remove interlamellar anions, and then encapsulated in alginate to prevent its intumescence, based on the patent BR1020140178430.

The encapsulated particles were packed in a fixed bed column and the adsorption process was studied using a complete Central Composite Rotational Design (CCRD), whose variables and answers are shown in Chart 1. To evaluate the effect of the mass of adsorbent, flow and temperature on the breaktrough and exhaustion times, 17 trials were performed (with 3 repetitions at the central point).

Chart 1. Variables and answers of the CCRD

\begin{tabular}{|c|c|c|c|}
\hline Mass (g) & $\begin{array}{c}\text { Flow } \\
(\mathbf{m L} / \mathbf{m i n})\end{array}$ & $\begin{array}{c}\text { Temp. } \\
(\mathbf{(} \mathbf{C})\end{array}$ & $\begin{array}{c}\text { Answers } \\
(\mathbf{m i n})\end{array}$ \\
\hline$-1.68(6.0)$ & $-1.68(0.4)$ & $-1.68(25)$ & Breaktrough \\
$-1(7.2)$ & $-1(0.52)$ & $-1(32)$ & and \\
$0(9.0)$ & $0(0.7)$ & $0(42.5)$ & exhaustion \\
$+1(10.8)$ & $+1(0.88)$ & $+1(53)$ & times of each \\
$+1.68(12.0)$ & $+1.68(1.0)$ & $+1.68(60)$ & adsorbate \\
\hline
\end{tabular}

The breaktrough and exhaustion times are defined as the moment when the concentration ' $C$ ' of the adsorbate on the column exit reaches $10 \%$ and $90 \%$ of the inlet concentration ('Co'), respectively. The concentration of sugars and inhibitors was measured with High Performance Liquid Chromatography (HPLC). The sugars analyzed were glucose (GLI), xylose (XIL) and arabinose (ARA), and the inhibitors analyzed were acetic acid (AA), furfural (FUR) and hydroximethylfurfural (HMF). Based on the CCRD, the best condition for the detoxification was maximum mass and flow, and intermediate temperature $\left(12.0 \mathrm{~g}, 1.0 \mathrm{~mL} / \mathrm{min}, 42.5^{\circ} \mathrm{C}\right)$. This condition is presented in Image 1.

Image 1. Detoxification results in the best condition

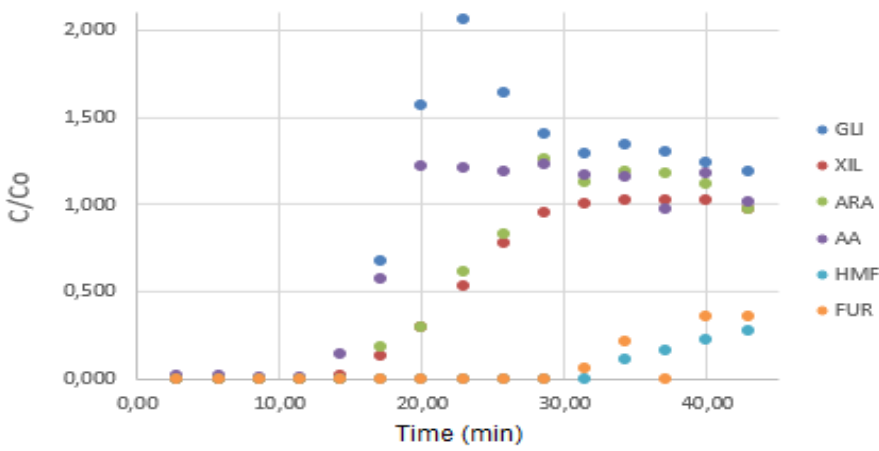

Although acetic acid could not be separated from the sugars, the process was able to seletively remove the furanics, which are the main inhibitors, thus allowing the detoxification of the hydrolyzate.

\section{Conclusions}

The detoxification process developed was capable of seletively removing the furanics inhibitors from the hydrolyzate. Acetic acid and sugars were not separated.

\section{Acknowledgement}

The authors are grateful for the support from CNPq/PIBIC and CAPES.

\footnotetext{
${ }^{1}$ Conab. Companhia Nacional de Abastecimento. Acompanhamento da safra brasileira de cana-de-açúcar, 2019

${ }^{2}$ Canilha, L.; Chandel, A. K.; Milessi, T. S. S.; Antunes, F. A. F.; Freitas, W. L. C.; Felipe, M. G. A.; Silva, S. S. J. Biomed. Biotec. 2012.

${ }^{3}$ Santos, M. L.; Lima, O. J.; Ciuffi, K. J.; Galefi, P. S. Química Nova, v. 34 n. 3. 2011, p. 507-511.
} 